\title{
Design of Control System for Forced Dynamics Control of an Electric Drive Employing Linear Permanent Magnet Synchronous Motor
}

\author{
Ján VITTEK, Ján MICHALÍK, Vladimír VAVRÚŠ, Vladimír HORVÁTH \\ University of Zilina, Faculty of Electrical Engineering \\ Univerzitná 1, 01026 Zilina, Slovak Republic \\ jan.vittek@fel.utc.sk
}

\begin{abstract}
The paper presents forced dynamics control of an electric drive with linear permanent magnet synchronous motor. This control method offers an accurate realisation of a dynamic speed response, which can be selected for given application by the user. In addition to this, the angle between stator current vector and moving part flux vector are maintained mutually perpendicular as it is in conventional vector control. To achieve prescribed speed response derived control law requires an external force information, which is obtained from the set of observers. The first set of observers is based on sliding-mode, while the second observer is classical full-state observer and exploits information of the position sensor. Simulations of the overall control system together with preliminary experimental results for the drive with rotational synchronous motor predict intended performance of the drive.
\end{abstract}

\section{INTRODUCTION}

The exploitation of linear AC motors for industrial and transportation applications is increasing. In this paper, speed control system for linear permanent magnet synchronous motor (LPMSM) is developed. This system enables to prescribe speed profile and settling time of the drive or vehicle and such way substantially contribute to the gentle load handling or to the travel comfort of passengers during speed transients. The conventional vector control methods can also prescribe shape of acceleration for the drive, but the settling time of the overall control system during speed transients depends on external disturbances.
Developed speed control system for LPMSM is based on forced dynamics control principles and principles of vector control. The forced dynamics control method is a new method for control of a.c. drives based on principle of feedback linearisation [1], [2]. The main reason for utilising of this method is that it enables to design control algorithm for the drive, which has precisely defined the profile of the acceleration and speed including settling time. The prescribed acceleration can therefore sufficiently exploits the limits determined by the maximum electrical force of the linear motor.

Mutual orthogonality of the force producing linear stator current vector and moving part magnetic flux vector is maintained, as it is usual for conventional vector controlled rotational drives with PMSM [3], [4].

To achieve prescribed settling time during speed transients the information about external force is needed. The estimate of external force together with the estimate of translation speed is obtained from the observers. Two various sets of observers are developed and compared. The first set is based on sliding-mode and to avoid chattering of the estimated variable, the observer is completed with another one, which has filtering effect. The second observer is designed as third order state observer, which exploits the measured position of the drive or vehicle.

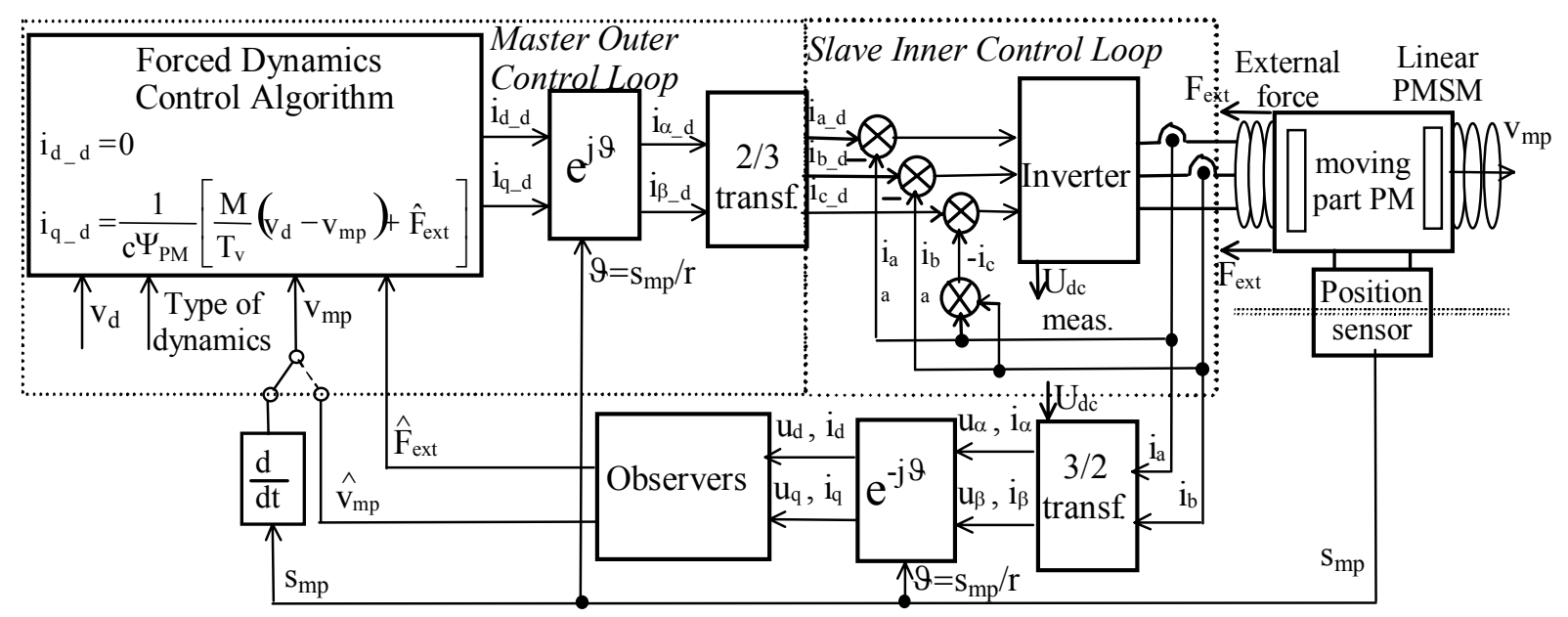

Fig. 1 Overall LPMSM control system block diagram 
The overall control system for LPMSM has a nested structure shown in Fig. 1, comprising an outer master control loop and inner slave control loop. Outer control loop computes such demanded stator currents, which realises the closed loop prescribed dynamic behaviour of the drive. This way selected operational modes with defined acceleration and speed profile can be prescribed. The inner slave control loop forces real three-phase stator currents to follow their computed demands from master algorithm with negligible lag via control of power electronic switches.

\section{CONTROL ALGORITHM DESIGN}

Forced dynamics control of the LPMSM exploits principles of feedback linearisation and principles of vector control. Firstly, the model of LPMSM is formulated in the d_q co-ordinate system, which is coupled to the moving part:

$$
\begin{aligned}
& \frac{\mathrm{ds}_{\mathrm{mp}}}{\mathrm{dt}}=\mathrm{v}_{\mathrm{mp}} \text {, } \\
& \frac{\mathrm{dv}_{\mathrm{mp}}}{\mathrm{dt}}=\frac{1}{\mathrm{M}}\left[\mathrm{c}\left(\Psi_{\mathrm{d}} \mathrm{i}_{\mathrm{q}}-\Psi_{\mathrm{q}} \mathrm{i}_{\mathrm{d}}\right)-\mathrm{F}_{\mathrm{ext}}\right], \\
& \frac{\mathrm{d}}{\mathrm{dt}}\left[\begin{array}{c}
\mathrm{i}_{\mathrm{d}} \\
\dot{\mathrm{i}}_{\mathrm{q}}
\end{array}\right]=\left[\begin{array}{cc}
-\mathrm{R}_{\mathrm{s}} / \mathrm{L}_{\mathrm{d}} & \mathrm{pv}_{\mathrm{mp}} \mathrm{L}_{\mathrm{q}} / \mathrm{rL}_{\mathrm{d}} \\
-\mathrm{pv_{ \textrm {mp } }} \mathrm{L}_{\mathrm{d}} / \mathrm{rL}_{\mathrm{q}} & -\mathrm{R}_{\mathrm{s}} / \mathrm{L}_{\mathrm{q}}
\end{array}\right]\left[\begin{array}{l}
\mathrm{i}_{\mathrm{d}} \\
\mathrm{i}_{\mathrm{q}}
\end{array}\right]- \\
& -\frac{\mathrm{pv}_{\mathrm{mp}}}{\mathrm{rL}_{\mathrm{q}}}\left[\begin{array}{c}
0 \\
\Psi_{\mathrm{PM}}
\end{array}\right]+\left[\begin{array}{cc}
1 / \mathrm{L}_{\mathrm{d}} & 0 \\
0 & 1 / \mathrm{L}_{\mathrm{q}}
\end{array}\right]\left[\begin{array}{l}
\mathrm{u}_{\mathrm{d}} \\
\mathrm{u}_{\mathrm{q}}
\end{array}\right]
\end{aligned}
$$

where, $\left[i_{d}, i_{q}\right]^{T}$ and $\left[u_{d}, u_{q}\right]^{T}$ are, respectively, column vectors of the LPMSM stator current and stator voltage components, $s_{\mathrm{mp}}$ and $\mathrm{v}_{\mathrm{mp}}$ are the position and velocity of the moving part, $c=3 p / 2 r$ where $p$ is number of motor pole-pairs and $\mathrm{r}$ is a constant parameter of LPMSM, which depends on the linear motor structure having the dimensions of length, $\mathrm{F}_{\text {ext }}$ is the external force, $\mathrm{R}_{\mathrm{s}}$ is the phase resistance, $\mathrm{L}_{\mathrm{d}}$ and $\mathrm{L}_{\mathrm{q}}$ are the direct and quadrature phase inductances, $\Psi_{\mathrm{PM}}$ is the permanent magnet linkage flux and $M$ is the mass of the linear motor moving part plus the equivalent mass of the driven mechanism.

\section{A2. Development of Control Algorithm}

Secondly the principles of feedback linearistion enable to formulate the linearising function for speed of the moving part, which forces this translation speed to obey specified closed-loop differential equation. This equation is assumed linear, first order with a prescribed time constant, $\mathrm{T}_{\mathrm{v}}$ :

$\mathrm{a}_{\mathrm{mp}}=\frac{\mathrm{dv}_{\mathrm{mp}}}{\mathrm{dt}}=\frac{1}{\mathrm{~T}_{\mathrm{v}}}\left(\mathrm{v}_{\mathrm{d}}-\mathrm{v}_{\mathrm{mp}}\right)$.

The computation technique for feedback linearisation is to equate the right hand side of (2) with the right hand side of the corresponding motor equation(1b). This forces the nonlinear differential equation (1b) to have the same response as the linear equation (2). Thus:

$$
\frac{1}{\mathrm{M}}\left[\mathrm{c}\left(\Psi_{\mathrm{d}} \mathrm{i}_{\mathrm{q}}-\Psi_{\mathrm{q}} \mathrm{i}_{\mathrm{d}}\right)-\mathrm{F}_{\mathrm{ext}}\right]=\frac{1}{\mathrm{~T}_{\mathrm{v}}}\left(\mathrm{v}_{\mathrm{d}}-\mathrm{v}_{\mathrm{mp}}\right) \text {. }
$$

The following part of the control law is formulated on the basis of vector control, which requires mutual orthogonality between the rotor magnetic flux and stator current vectors. Following conventional approach [3] to achieve maximum magnetic flux up to nominal speed the current demand for the magnetic flux component in direct axis is set to zero:

$\mathrm{i}_{\mathrm{d}}=0$.

Setting $i_{d}=0$ in (3) on the assumption that the real current follows its demand, $i_{d}=i_{d_{d} d}$ and solving (3) for force producing component, $\mathrm{i}_{\mathrm{q} \mathrm{d}}$ yields the following master control algorithm formulated for stator current demands in the d-and q-axis:

$\mathrm{i}_{\mathrm{d}_{-} \mathrm{d}}=0$

$\mathrm{i}_{\mathrm{q}_{-} \mathrm{d}}=\frac{1}{\mathrm{c} \Psi_{\mathrm{PM}}}\left[\frac{\mathrm{M}}{\mathrm{T}_{\mathrm{v}}}\left(\mathrm{v}_{\mathrm{d}}-\mathrm{v}_{\mathrm{mp}}\right)+\hat{\mathrm{F}}_{\mathrm{ext}}\right]=\frac{\mathrm{Ma}_{\mathrm{mp}}+\hat{\mathrm{F}}_{\mathrm{ext}}}{\mathrm{c} \Psi_{\mathrm{PM}}}$.

This way the derived master control law (5) yields a moving part speed response with linear, first order dynamics and unity de gain:

$\mathrm{F}_{\mathrm{S}}(\mathrm{p})=\frac{\mathrm{v}_{\mathrm{mp}}(\mathrm{p})}{\mathrm{v}_{\mathrm{d}}(\mathrm{p})}=\frac{1}{1+\mathrm{pT} \mathrm{T}_{\mathrm{v}}}$.

The numerator of the derived control algorithm (5) consists of two parts. The first one contains the demanded output acceleration and creates dynamic force during transients. The second part covers the external force, which needs to be estimated. By changing the prescribed acceleration, $\mathrm{a}_{\mathrm{mp}}$, various operational modes of the drive can be realised.

\section{B2. Operational Control Modes}

Via proper definition of smooth mathematical functions for drive acceleration in (5), various operational modes can be achieved. Following modes were chosen as the examples: a) Direct acceleration control with constant acceleration (ramp), where the drive produces acceleration of a moving part following a demanded constant acceleration with negligible dynamic lag. In this case, demanded acceleration is determined by a constant demand of velocity, $\mathrm{v}_{\mathrm{d}}$ and the demanded acceleration time, $\mathrm{T}_{\mathrm{s}}$ :

$\mathrm{a}_{\mathrm{d}}=\frac{\mathrm{v}_{\mathrm{d}}}{\mathrm{T}_{\mathrm{s}}} \operatorname{sgn}\left(\mathrm{v}_{\mathrm{d}}-\mathrm{v}_{\mathrm{mp}}\right)$.

b) Direct acceleration control with linearly dependent acceleration (S-curve), where the drive produces linearly increasing and decreasing acceleration (constant jerk) during speed transients. The corresponding equations for the demanded acceleration can be easily derived, [5].

c) Linear first order speed response, which is the case already described during master control law development $\left(\mathrm{T}_{\mathrm{s}}=3 \mathrm{~T}_{\mathrm{v}}\right)$, therefore briefly:

$\mathrm{a}_{\mathrm{d}}=\frac{1}{\mathrm{~T}_{\mathrm{v}}}\left(\mathrm{v}_{\mathrm{d}}-\mathrm{v}_{\mathrm{mp}}\right)=\frac{3}{\mathrm{~T}_{\mathrm{s}}}\left(\mathrm{v}_{\mathrm{d}}-\mathrm{v}_{\mathrm{mp}}\right)$.

d) Second order speed response (fluent change of acceleration), where the drive acceleration is prescribed such way that the closed-loop system has a response given by the second order characteristic equation. In this case the derivative of demanded acceleration is done by (9) and to gain desired acceleration (9) needs to be integrated.

$\varepsilon=\frac{\mathrm{da}_{\mathrm{d}}}{\mathrm{dt}}=\ddot{\mathrm{v}}_{\mathrm{mp}}=-2 \xi \omega_{\mathrm{n}} \dot{\mathrm{v}}_{\mathrm{mp}}+\omega_{\mathrm{n}}^{2}\left(\mathrm{v}_{\mathrm{d}}-\mathrm{v}_{\mathrm{mp}}\right)$. 
If damping factor $\xi=1$ for critically damped system is chosen and the poles of the characteristic equation are purposely designed as coincident the settling time formula (10), where $n$ is order of the system, may be used to determine $\omega_{\mathrm{n}}$, which will fit chosen settling time:

$\mathrm{T}_{\mathrm{s}}=\frac{3}{2}(1+\mathrm{n}) \frac{1}{\omega_{\mathrm{n}}}$.

Ideal acceleration and speed responses based on described operational control modes are shown in Fig. 2.

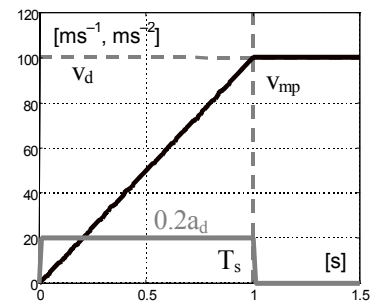

a) constant acceleration, ramp

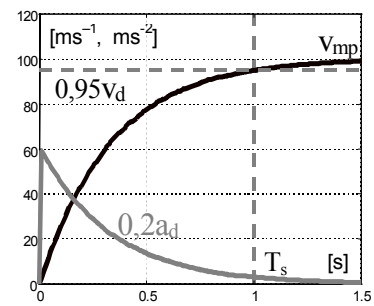

c) first order dynamic response

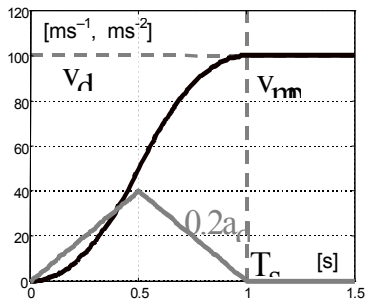

b) linear acceleration, S-curve

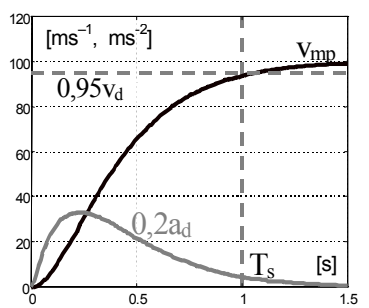

d) second order dynamic response
Fig. 2 Prescribed profiles of speed and accelerations

\section{C2. Representation of the Load}

An important feature of the designed control system is the representation of the driven mechanical load, which is shown in Fig. 3. Thus only the mass of motor moving parts, $M_{m}$ used is included in the forward path as a rigid body, moving without external force and friction [6]. Both, external force and friction are modelled in the feedback path, as it is shown. The justification for this is that the not completely known friction forces can be for some applications dominated, [7].

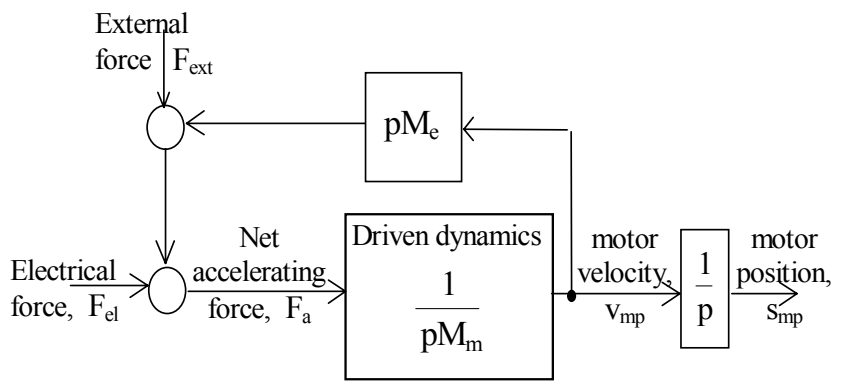

Fig. 3 Representation of the driven mechanical load

It is also important to note that it is unnecessary to provide an accurate model of the inverse load dynamics. Since the error in the value of moving mass, $M_{m}$ used can be represented as a dynamic load force, $\mathrm{M}_{\mathrm{e}} \mathrm{dv} / \mathrm{dt}$, and this together with any external force acts at the same point as $\mathrm{F}_{\text {ext }}$, then the estimate, $\mathrm{F}_{\text {ext }}$ from the observer will include both these forces and so both of them will be compensated.

\section{STATE ESTIMATION AND FILTERING}

The speed of moving part and external force, which are inputs for the master control algorithm are produced by the following set of observers. The first observer, which is based on stator current equation, works in pseudo-slidingmode, [8], [9] and generates an unfiltered estimate of translation speed. This observer is completed with filtering observer, which provides filtered speed estimate together with estimate of external force. The second observer, which exploits the measurement of motor position is full-state observer and provides the estimates of translation speed together with external force.

\section{A3. The pseudo-sliding-mode observer}

For the translation speed estimation pseudo-sliding-mode observer shown in Fig. 4 is used. The observer is based on a stator current $\mathrm{i}_{\mathrm{q}}$ equation, (1c) as a real time model but purposely using only the terms without $v_{m p}$ :

$\frac{\mathrm{di}_{\mathrm{q}}}{\mathrm{dt}}=-\frac{\mathrm{R}_{\mathrm{s}}}{\mathrm{L}_{\mathrm{q}}} \mathrm{i}_{\mathrm{q}}-\frac{\mathrm{pv}_{\mathrm{mp}}}{\mathrm{rL}_{\mathrm{q}}}\left(\mathrm{L}_{\mathrm{d}} \mathrm{i}_{\mathrm{d}}+\Psi_{\mathrm{PM}}\right)+\frac{1}{\mathrm{~L}_{\mathrm{q}}} \mathrm{u}_{\mathrm{q}}$.

The terms containing $\mathrm{v}_{\mathrm{mp}}$ in (11) are in observer model, (12) replaced by the correction input, $\mathrm{v}_{\mathrm{q}}$. Thus equation of the model $\mathrm{i}_{\mathrm{q}}$ component is:

$\frac{\mathrm{di}_{\mathrm{q}}^{*}}{\mathrm{dt}}=-\frac{\mathrm{R}_{\mathrm{s}}}{\mathrm{L}_{\mathrm{q}}} \mathrm{i}_{\mathrm{q}}^{*}+\frac{1}{\mathrm{~L}_{\mathrm{q}}} \mathrm{u}_{\mathrm{q}}-\mathrm{v}_{\mathrm{q}}$,

where $\mathrm{i}_{\mathrm{q}}^{*}$ is estimate of $\mathrm{i}_{\mathrm{q}}$ as in a conventional observer. In sliding-mode the estimate of $\mathrm{v}_{\mathrm{q}}$ is produced as fast switching of $U_{\max }$, (13a). However, the useful observer output is the continuous equivalent value of the rapidly switching $\mathrm{v}_{\mathrm{q}}$. Equation (13a) cannot directly generate $\mathrm{v}_{\text {eq }} \mathrm{q}$. Instead, a pseudo-sliding-mode observer, [8] may be formed by replacing (13a) with (13b):

$\mathrm{v}_{\mathrm{q}}=-\mathrm{U}_{\max } \operatorname{sgn}\left(\mathrm{i}_{\mathrm{q}}-\mathrm{i}_{\mathrm{q}}^{*}\right), \quad \mathrm{v}_{\mathrm{q} \text { eq }}=-\mathrm{K}_{\mathrm{sm}}\left(\mathrm{i}_{\mathrm{q}}-\mathrm{i}_{\mathrm{q}}^{*}\right)$,

where the gain, $\mathrm{K}_{\mathrm{sm}}$, is made as high as possible [10], [11] within the stability limit. For large $\mathrm{K}_{\mathrm{sm}}$, the error between real current and fictitious observer current is driven almost to zero, resulting in (14):

$\mathrm{v}_{\mathrm{q} \text { eq }}=\frac{-\mathrm{pv}_{\mathrm{mp}}}{\mathrm{rL}_{\mathrm{q}}}\left(\mathrm{L}_{\mathrm{d}} \mathrm{i}_{\mathrm{d}}+\Psi_{\mathrm{PM}}\right)$

and this may be manipulated to yield an unfiltered velocity estimate, $v^{*}{ }_{m p}$. Thus:

$\mathrm{v}_{\mathrm{mp}}^{*}=\frac{-\mathrm{rL}_{\mathrm{q}} \mathrm{v}_{\mathrm{q}_{-} \mathrm{eq}}}{\mathrm{p}\left(\mathrm{L}_{\mathrm{d}} \mathrm{i}_{\mathrm{d}}+\Psi_{\mathrm{PM}}\right)}$.

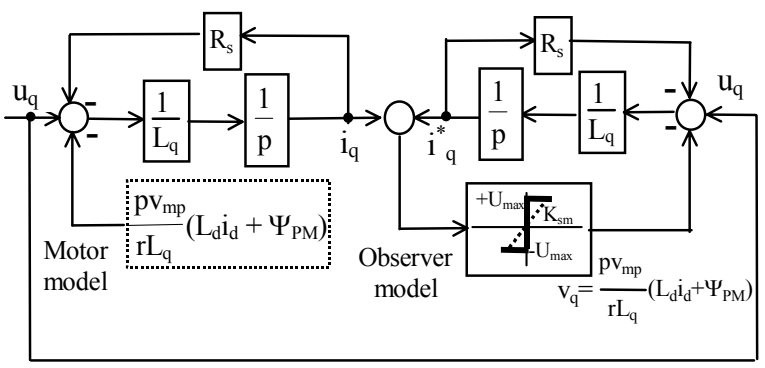

Fig.4 Block diagram of pseudo-sliding-mode observer 


\section{B3. Filtering Observer}

Filtering function of the velocity estimate, (15) is performed by filtering observer, which provides also the external force estimate, [12], [13]. The real time model of this observer is based on the motor force equation (1b), which is augmented by the second state differential equation, $\mathrm{dF}_{\text {ext }} / \mathrm{dt}=0$, for assumption of the piecewise constant external force, $\mathrm{F}_{\text {ext }}$. The observer correction loops are actuated by the error between the unfiltered speed estimate, $\mathrm{v}_{\mathrm{mp}}{ }_{\mathrm{m}}$, from the pseudo-sliding-mode observer and the filtered translation speed estimate, $\hat{v}_{\mathrm{mp}}$, from the real time model output. The filtering observer equations are:

$\mathrm{e}_{\mathrm{v}}=\mathrm{v}_{\mathrm{mp}}^{*}-\hat{\mathrm{v}}_{\mathrm{mp}}$,

$\frac{\mathrm{d} \hat{\mathrm{v}}_{\mathrm{mp}}}{\mathrm{dt}}=\frac{1}{\mathrm{M}}\left[\mathrm{c}\left(\Psi_{\mathrm{d}} \mathrm{i}_{\mathrm{q}}-\Psi_{\mathrm{q}} \mathrm{i}_{\mathrm{d}}\right)-\hat{\mathrm{F}}_{\text {ext }}\right]+\mathrm{k}_{\mathrm{v}} \mathrm{e}_{\mathrm{v}}$,

$\frac{\mathrm{d} \hat{\mathrm{F}}_{\text {ext }}}{\mathrm{dt}}=0+\mathrm{k}_{\mathrm{F}} \mathrm{v}_{\mathrm{e}}$.

This is a conventional second order linear observer with a correction loop characteristic polynomial, which may be chosen via the gains, $\mathrm{k}_{\mathrm{v}}$ and $\mathrm{k}_{\mathrm{F}}$ to yield the desired balance of filtering between the noise from the measurements of $i_{d}$ and $i_{q}$ and the noise from the pseudo-sliding-mode velocity estimate. Transfer function of the observer shown in Fig. 5 is:

$$
\mathrm{F}(\mathrm{p})=\frac{\hat{\mathrm{v}}_{\mathrm{mp}}(\mathrm{p})}{\mathrm{v}_{\mathrm{mp}}^{*}(\mathrm{p})}=\frac{\mathrm{pk}_{\mathrm{v}}+\mathrm{k}_{\mathrm{F}} / \mathrm{M}}{\mathrm{p}^{2}+\mathrm{pk}_{\mathrm{v}}+\mathrm{k}_{\mathrm{F}} / \mathrm{M}} .
$$

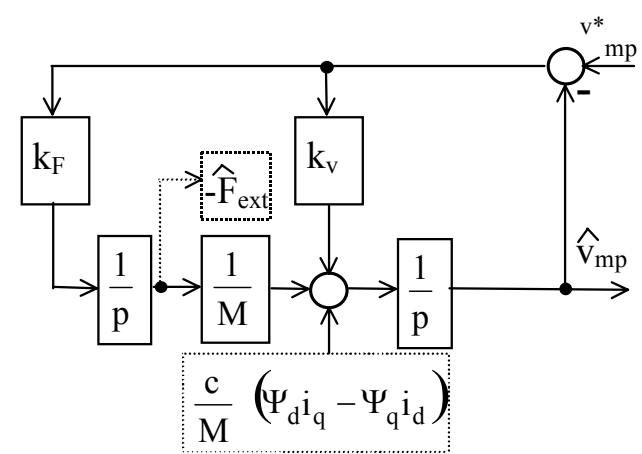

Fig.5 Block diagram of filtering observer

The observer gains may be chosen to yield a non-oscillatory state estimation error transient with prescribed settling time, $\mathrm{T}_{\mathrm{s}}$. Based on settling time formula, (10) the observer poles can be placed at $\omega_{0}=9 / 2 \mathrm{~T}_{\mathrm{s}}$ yielding desired polynomial:

$\left(\mathrm{p}+9 / 2 \mathrm{~T}_{\mathrm{s}}\right)^{2}=\mathrm{p}^{2}+9 / \mathrm{T}_{\mathrm{s}}+81 /\left(4 \mathrm{~T}_{\mathrm{s}}^{2}\right)$,

which yields observer gains:

$\mathrm{k}_{\mathrm{v}}=9 / \mathrm{T}_{\mathrm{s}}, \quad \mathrm{k}_{\mathrm{F}}=81 \mathrm{M} / 4 \mathrm{~T}_{\mathrm{s}}^{2}$.

Although the external force is assumed constant in the formulation of the observer real time model, the estimate of $\hat{\mathrm{F}}_{\mathrm{ext}}$ will follow a time varying external force and will do so more faithfully as $T_{s}$ is reduced, but at the expense of sensitivity to any noise contaminating the speed estimate.

\section{C3. State Observer Based on Position Measurement}

Since a direct measurement of the external force is assumed unavailable, its estimate for the master control law can be provided by a standard full-states observer, which exploits the position measurement. Real time model of the observer is based on the motor position, (1a) and velocity, (1b) equations augmented again by the third state equation for piecewise constant external force. The error between real position and estimated position, $\mathrm{e}_{\mathrm{s}}=\mathrm{S}_{\mathrm{mp}}-\hat{\mathrm{S}}_{\mathrm{mp}}$ is added with corresponding gain into every observer correction loop:

$$
\begin{aligned}
& \frac{d \hat{s}_{m p}}{d t}=\hat{v}_{m p}+K_{s} e_{s}, \\
& \frac{d \hat{v}_{m p}}{d t}=\frac{1}{M}\left[c\left(\Psi_{d} i_{q}-\Psi_{q} i_{d}\right)-\hat{F}_{e x t}\right]+K_{v} e_{s}, \\
& \frac{d \hat{F}_{e x t}}{d t}=0+K_{F} e_{s} .
\end{aligned}
$$

Block diagram of observer for estimates of external force and translation speed of the moving part is shown in Fig. 6.

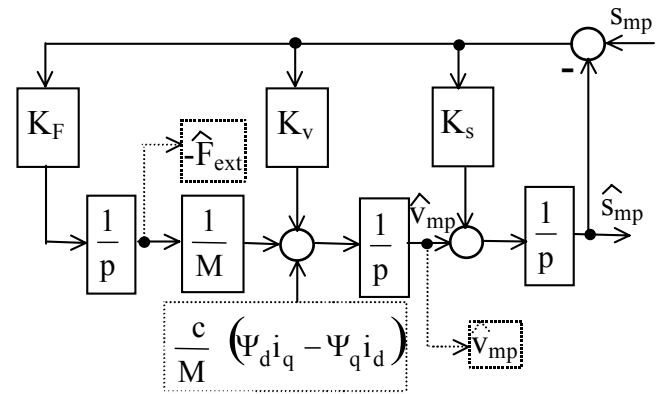

Fig. 6 Moving part speed and external force observer

The observer transfer function is given as:

$$
\mathrm{F}_{\mathrm{O}}(\mathrm{p})=\frac{\hat{\mathrm{s}}_{\mathrm{mp}}(\mathrm{p})}{\mathrm{s}_{\mathrm{mp}}(\mathrm{p})}=\frac{\mathrm{p}^{2} \mathrm{~K}_{\mathrm{s}}+\mathrm{pK} \mathrm{K}_{\mathrm{v}}+\mathrm{K}_{\mathrm{F}} / \mathrm{M}}{\mathrm{p}^{3}+\mathrm{p}^{2} \mathrm{~K}_{\mathrm{s}}+\mathrm{pK} \mathrm{K}_{\mathrm{v}}+\mathrm{K}_{\mathrm{F}} / \mathrm{M}} \text {. }
$$

If the observer poles are chosen as coincident and placed at $\mathrm{p}=-6 / \mathrm{T}_{\text {so }}$ with settling time, $\mathrm{T}_{\mathrm{so}}$, then the desired polynomial is:

$\left(\mathrm{p}+\frac{6}{\mathrm{~T}_{\text {so }}}\right)^{3}=\mathrm{p}^{3}+\frac{18}{\mathrm{~T}_{\text {so }}} \mathrm{p}^{2}+\frac{108}{\mathrm{~T}_{\text {so }}^{2}} \mathrm{p}+\frac{216}{\mathrm{~T}_{\text {so }}^{3}}$.

Comparing characteristic polynomials (21) and (22) yields:

$\mathrm{K}_{\mathrm{s}}=\frac{18}{\mathrm{~T}_{\mathrm{so}}}, \mathrm{K}_{\mathrm{v}}=\frac{108}{\mathrm{~T}_{\mathrm{so}}^{2}}$ and $\mathrm{K}_{\mathrm{F}}=\frac{216 \mathrm{M}}{\mathrm{T}_{\mathrm{so}}^{3}}$.

The force estimate, $\hat{\mathrm{F}}_{\text {ext }}$ will again follow arbitrary time varying external force and will do it more closely as $\mathrm{T}_{\mathrm{so}}$ is reduced.

\section{DESIGNED CONTROL SYSTEM VERIFICATION}

Verifications of the overall designed control system were performed in two steps. The first one was the verification by simulation and the second step was the preliminary experiments with rotational PMSM.

The simulations of the design control system were performed with the LPMSM having parameters: $\mathrm{P}_{\mathrm{n}}=800 \mathrm{~W}$, 
$\mathrm{p}=3, \mathrm{r}=0.156 \mathrm{~m}, \mathrm{R}_{\mathrm{s}}=0,59 \Omega, \mathrm{L}_{\mathrm{d}}=3,7 \mathrm{mH}, \mathrm{L}_{\mathrm{q}}=3.5 \mathrm{mH}$ and $\Psi_{\mathrm{PM}}=0,3 \mathrm{Vs}$. The total load mass and external force are $\mathrm{M}=5 \mathrm{~kg}$ and $\mathrm{F}_{\text {ext }}=250 \mathrm{~N}$. Settling time for both types of observers was chosen as $\mathrm{T}_{\mathrm{so}}=10 \mathrm{~ms}$. A sampling frequency of $10 \mathrm{kHz}$ achieved during experiments with rotational PMSM was assumed also for the power electronics switches of inverter in simulation.

All simulations show the designed system response to a step speed demand of $\mathrm{v}_{\mathrm{dem}}=10 \mathrm{~ms}^{-1}$ applied for time interval $\mathrm{t} \in(0,0,25] \mathrm{s}$ with zero initial states of all state variables and prescribed settling time $T_{\mathrm{s}}=0,1 \mathrm{~s}$ followed immediately by step speed demand of $\mathrm{v}_{\mathrm{dem}}=-10 \mathrm{~ms}^{-1}$ applied for time interval $\mathrm{t} \in[0,250,6) \mathrm{s}$ with twice longer settling time. The external force $\mathrm{F}_{\text {ext }}=250 \mathrm{~N}$ is applied at $\mathrm{t}=0,15 \mathrm{~s}$, which drops to zero at $\mathrm{t}=0,25 \mathrm{~s}$. Negative external force is applied again at $\mathrm{t}=0,5 \mathrm{~s}$ when speed is also negative. The simulations were performed for both types of the designed observers.

Simulation results for described dynamics show demanded speed, $\mathrm{v}_{\mathrm{d}}$, real speed, $\mathrm{v}_{\mathrm{mp}}$, estimated speed from filtering observer or full-state observer, $\hat{v}_{\mathrm{mp}}$, together with applied $\mathrm{F}_{\text {ext }}$ and estimated external force $\mathrm{F}_{\text {ext }}^{\wedge}$ as a functions of time.

Fig. 7 shows control system ideal response to prescribed first order dynamics, when pseudo-sliding-mode observer completed with filtering observer were employed (translation speed is multiplied by factor 10 and external force is divided by factor 5 in all simulation results presented further).

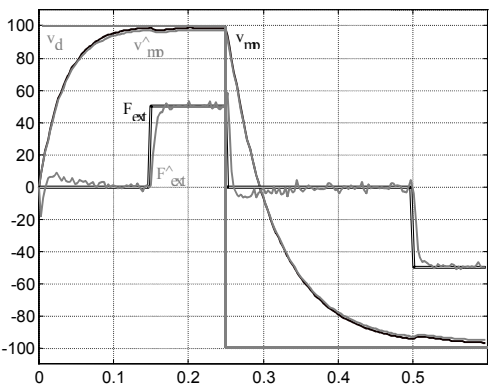

Fig. 7 Simulation results for the first order speed dynamics

Ideal control system response to the prescribed first order dynamic for full-state observer are shown in Fig. 8.

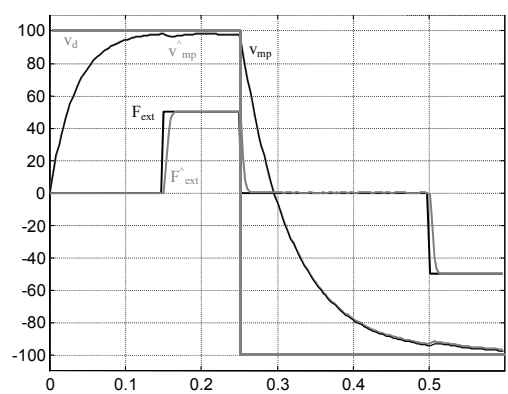

Fig. 8 Simulation results for the first order speed dynamics

As can be seen from both figures the prescribed settling time and dynamics of the system were achieved. From the time function of estimated external force it is possible to observe correct design of observer poles, when $95 \%$ of estimated force is achieved at settling time $\mathrm{T}_{\mathrm{s}}=0,01 \mathrm{~s}$.

Fig. 9a shows both stator current components and Fig. 9b shows estimated speed of pseudo-sliding-mode observer.

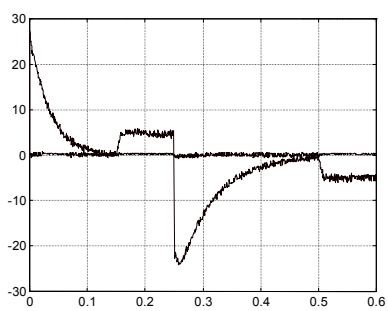

a) $i_{d}$ and $i_{q}=f(t)$

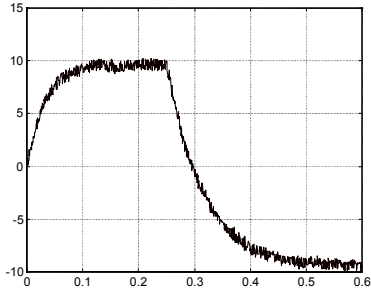

b) $\mathrm{v}_{\mathrm{mp}}^{*}=\mathrm{f}(\mathrm{t})$
Fig. 9 Stator current components and estimated speed of pseudosliding-mode observer

To save some space, simulation results for ramp speed demands are shown for full-state observer and simulations of second order dynamics are shown for pseudo-sliding-mode observer only. To get more realistic simulations the 12 bits $\mathrm{AD}$ converters (final length of digital word) for sensing of moving part position and for sensing both stator current components were included into simulations.

Fig. 10a shows control system response to the prescribed ramp speed demand and control system response to the second order dynamics is shown in Fig. 10b. As can be seen from both figures the prescribed system dynamics were achieved (demanded speed or 95\% of the demanded speed is achieved at prescribed settling time).

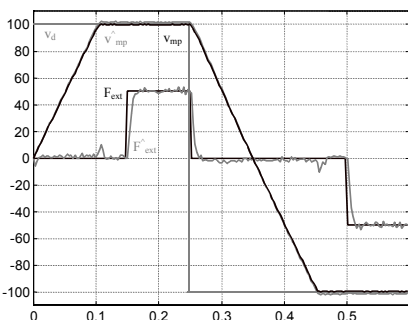

a) ramp speed demand

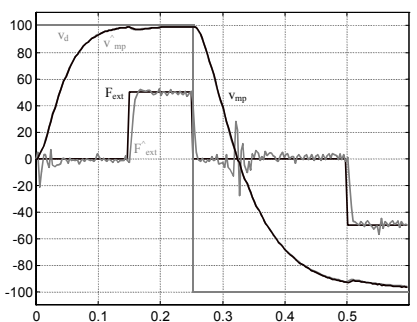

b) second order dynamic
Fig. 10a,b Simulation results for ramp speed demand and second order dynamic

Current components $i_{d}$ and $i_{q}$ for ramp speed demand and second order dynamic are shown in Fig. 11a,b. The ratio among the peak currents of the first order dynamic, Fig. 9a, the second order dynamic, Fig. 11b and ramp speed demand Fig. $11 \mathrm{a}$ is $3: 1,5: 1$ as it is clear also from acceleration peaks of Fig. 2.
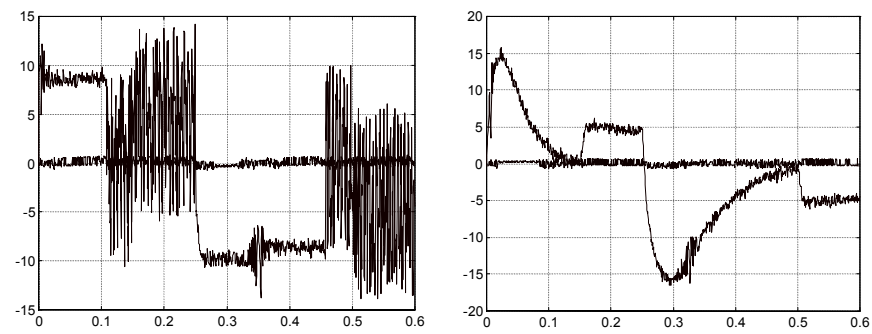

Fig. 11 Stator current components as a function of time

Due to the absence of experimental bench with LPMSM the preliminary experiments were carried out with rotational PMSM Dutym Ax-DS having the following parameters: $\mathrm{P}_{\mathrm{n}}=375 \mathrm{~W}$ at $\omega_{\mathrm{n}}=314,16 \mathrm{rad} / \mathrm{s}, \quad \mathrm{p}=3, \quad \mathrm{R}_{\mathrm{s}}=36,5 \Omega$, $\mathrm{L}_{\mathrm{d}}=\mathrm{L}_{\mathrm{q}}=50 \mathrm{mH}, \Psi_{\mathrm{PM}}=0,312 \mathrm{Vs}$ and $\mathrm{J}_{\mathrm{r}}=0,032 \mathrm{kgm}^{2}$. 
Fig. 12 shows the measured results for forced dynamics control of the rotational drive. Speed response to the speed demand, $\omega_{\mathrm{d}}=70 \mathrm{rads}^{-1}$ and settling time, $\mathrm{T}_{\mathrm{s}}=0,5 \mathrm{~s}$ are recorded together with measured stator current. Fig. 13a shows speed response to the first order dynamic, Fig. 13b to the ramp speed demand and Fig. 13c response to the second order dynamics. As can be seen from all three figures the prescribed speed dynamics of rotational drive were achieved.

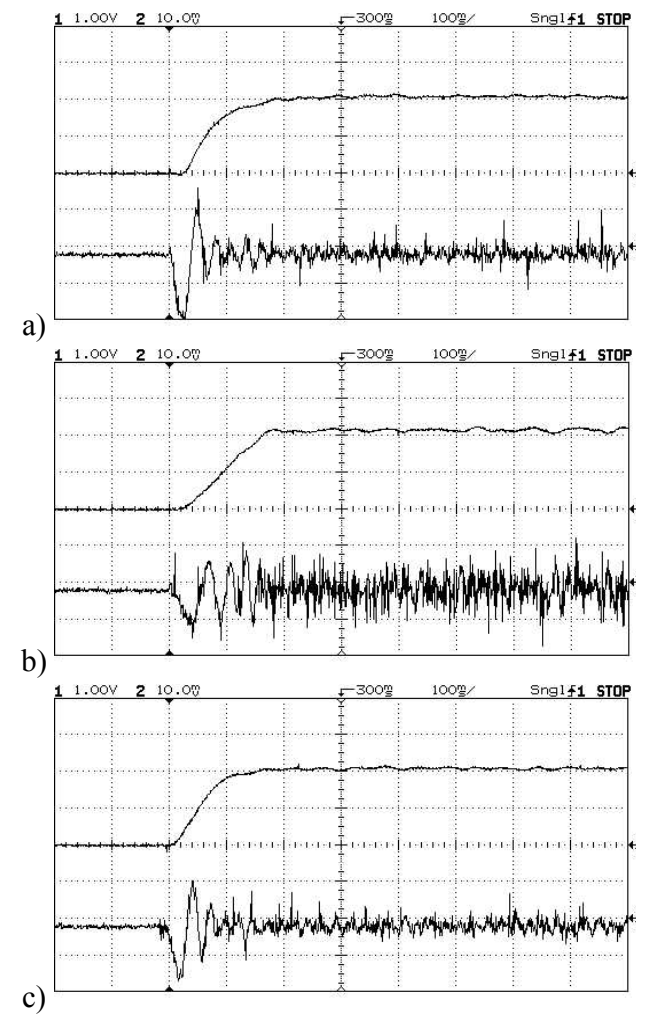

Fig. 12 Experimental verification with rotational PMSM

Based on theoretical predictions and simulations it was found that the operational mode with second order dynamics enables fluent change of the load acceleration at relatively low current peak demand and therefore is very suitable for gentle handling of the load during speed transients.

\section{CONCLUSIONS AND SUGGESTIONS FOR FURTHER WORK}

The presented simulation results indicate that the designed control system for the industrial and traction drives exploiting LPMSM operates properly. It can be observed from Fig. 7 and Fig. 8 for the first order dynamics, from Fig. 10a for ramp speed demand and from Fig. 10b for the second order speed demand that prescribed dynamics were achieved as it was intended.

The preliminary experimental results of this new control system for electric drives employing rotational PMSM indicates possibility that the prescribed speed dynamics with counteraction of external disturbances are attainable with realistic errors in the assumed motor parameters.

The designed pseudo-sling-mode observer and full-state observer for translation speed and an external load force, which create substantial part of the control system, have nonoscillatory character and properly estimate the speed of moving part and external disturbance. In spite of this observers are subject of further improvements and therefore it is desirable to investigate also another types of observers.

The experimental verification of the design overall control system for the drive exploiting LPMSM therefore should be sought as a continuation of this work.

\section{ACKNOWLEDGMENT}

The authors gratefully acknowledge the contributions of the 'Deutscher Akademischer Austauschdienst' for funding the scientific project No.04/2003 " $R \& D$ of Sensorless Microprocessor Controlled Drives Employing Synchronous Rotating and Linear Motors', further 'Czech and Slovak Joined Commission' for funding bilateral project No. 016/023 "R\&D of a Modern Controlled AC Drives", and 'Slovak Ministry of Education' in Bratislava for financial support of the program No. 2003 SP 51/028 09 00/028 0905 „Improvement of quality and exploitation of electric energy for traction and general applications “.

\section{REFERENCES}

[1] A. Isidori, Nonlinear Control Systems, Springer-Verlag, Berlin, DE: 1989.

[2] M. Krstic, I. Kanellakopoulis, I., P.V. Kokotovic, Nonlinear and Adaptive Control Design, John Wiley and Sons, New York, NY: 1995.

[3] I. Boldea, S.A. Nasar, Vector Control of AC Drives, $2^{\text {nd }}$ edition, CRC Press, 1992.

[4] W. Leonhard, Control of Electrical Drives, Springer-Verlag, Berlin, DE: 1985.

[5] J. Vittek, S.J. Dodds. Forced Dynamics Control of Electric Drives, EDIS Zilina, SK, 2003.

[6] K. Ohnishi, M. Morisawa, "Motion Control Taking Environmental Information into Account," in Proceedings of the EPE PEMC Conference, Cavtat, Croatia, 2002.

[7] S.J. Dodds, H. Wild. "Real-time Identification of the Friction Coefficient of a Rolling Guided High Dynamic Linear Motor," Proceedings of the Control'98 Conference, United Kingdom, 1998.

[8] V.I. Utkin, Sliding Modes in Control and Optimisation, SpringerVerlag, Berlin, DE, 1992

[9] O. Aguilar, A.G. Loukianov, J.M. Canedo, "Observer-based Sliding Mode Control of Synchronous Motor," in Proceedings of the IFAC Congress, Guadalajara, Mexico 2002.

[10] S.S. Ryvkin, "Sliding Mode Based Observer for Sensorless Permanent Magnet Synchronous Motor Drive," Proceedings of the EPE-PEMC Conference, Budapest, Hungary, 1996.

[11] J. Gyeviki, I.T. Toth, K. Rozsahegyi, "Sliding Mode Control and its Application on an Servo-pneumatic Positioning System," Transactions on Automatic Control and Computer Science, University of Timosoara, vol. 49, Romania, 2004.

[12] N.S. Nise. Control System Engineering, The Benjamin Cumming Publ. Co., Redwood City, CA, 1995.

[13] K. Urbanski, K. Zawirski, "Sensorless Control of SMPM with Modified Observer Structure," in Proceedings of the EPE-PEMC Conference, Cavtat, Croatia, 2002.

[14] S. Brock, J. Deskur, K. Zawirski, "A Modified Approach to the Design of Robust Speed and Position Control of Servo Drives," Proceedings of the EPE-PEMC Conference, Cavtat, Croatia, 2002.

[15] J. Timko, J. Žilková, D. Balara, "Applications of Artificial Neural Nets in Electric Drives,” Calypso Košice, Slovak Republic, 2002.

[16] G. Knerczer, L. Nagy, P. Korondy, S. Peresztegi, T. Mezo: "Compact Motors and Drives for Electric Vehicles", Automatika, (1-2), 47-55. 